\title{
It's better to be ignorant of our moral enhancement: A reply to Zambrano
}

In a recent issue of Bioethics, I argue that compulsory moral bioenhancement should be administered covertly. Alexander Zambrano has criticized this argument on two fronts. First, contrary to my claim, Zambrano claims that the prevention of ultimate harm by covert moral bioenhancement fails to meet conditions for permissible liberty-restricting public health interventions. Second, contrary to my claim, Zambrano claims that covert moral bioenhancement undermines autonomy to a greater degree than does overt moral bioenhancement. In this paper, I rebut both of these arguments, then finish by noting important avenues of research that Zambrano's arguments motivate.

In a recent article in this journal, ${ }^{1}$ Alexander Zambrano has criticized my argument that if moral bioenhancement (MBE) ought to be compulsory, as some authors claim, ${ }^{2}$ then it ought to be administered covertly - that it is morally preferable for compulsory MBE to be administered covertly rather than overtly. ${ }^{3}$ Among other claims, my argument for the moral preferability of covert MBE relies on a sub-argument that compulsory MBE is a matter of public health. Since its administration is a matter of public health, the ethics of public health interventions ought to guide judgments about the permissibility of the administration of compulsory MBE. And under the frameworks for public health ethics, a covert administration turns out to be morally preferable to an overt administration.

\footnotetext{
${ }^{1}$ Zambrano, A. (2019). Covert moral bioenhancement, public health, and autonomy. Bioethics, (October 2018), 2-5. https://doi.org/10.1111/bioe.12567

${ }^{2}$ Persson, I., \& Savulescu, J. (2008). The Perils of Cognitive Enhancement and the Urgent Imperative to Enhance the Moral Character of Humanity. Journal of Applied Philosophy, 25(3), 162-177. https://doi.org/10.1111/j.1468-5930.2008.00410.x; Persson, I., \& Savulescu, J. (2014). Unfit for the Future: The Need for Moral Enhancement. Oxford University Press.

${ }^{3}$ Crutchfield, P. (2019). Compulsory moral bioenhancement should be covert. Bioethics, 33(1), 112-121. https://doi.org/10.1111/bioe.12496
} 
I finish the article by considering a common objection to the notion that we ought to be morally enhanced, that to do so would be to undermine the autonomy of the enhanced. I argue that to the extent that compulsory MBE undermines a person's moral judgments' independence from external influence (but I don't think it does), it makes no difference whether the administration is covert or overt — if compulsory MBE violates independence, covert and overt administrations do so equally. However, I argue that an overt program undermines to a greater degree the authenticity of a person's moral judgments. Since authenticity is plausibly a component of autonomy, a covert administration undermines a person's autonomy to a lesser degree than an overt administration.

Zambrano rejects both the argument that compulsory MBE is a matter of public health as well as the argument that covert administration of MBE undermines autonomy to a lesser degree than an overt administration. In what follows, I offer a reply to his arguments and in doing so more firmly establish the moral preferability of a covert administration of MBE.

\section{Public health and covert MBE}

Persson and Savulescu argue that MBE ought to be compulsory on the grounds that to so improve the population's moral capacities is necessary to prevent ultimate harm, the sort of harm that may result from, for examples, catastrophic climate change or the proliferation of nuclear weapons or other weapons of mass destruction. ${ }^{4}$ Some authors have argued that we ought to

\footnotetext{
${ }^{4}$ Op. cit. note 2
} 
pursue MBE, but that it should be only voluntary rather than compulsory. ${ }^{5}$ Further, Vojin Rakić argues that the pursuit of happiness, rather than the prevention of ultimate harm, justifies MBE. ${ }^{6}$ Alternatively, according to Rakić we are obligated to improve our own moral judgments, and that the way to do this is to use MBE to create enhanced moral agents so that they can show us what and how to judge. ${ }^{7}$ So although the prevention of ultimate harm is one way to justify MBE, it is not the only way. Other authors claim that we shouldn't pursue MBE not because to do so would undermine freedom or autonomy, but because MBE is not something that is technologically feasible, given the social, psychological, and biological complexities of moral judgment and behavior. ${ }^{8}$

My argument assumes that compulsory MBE is morally justified on the grounds that it is necessary to prevent ultimate harm. I then focus on the implications of this proposal. My argument that compulsory MBE ought to be covert starts with the claim that preventing ultimate

${ }^{5}$ Rakić, V. (2014). Voluntary moral enhancement and the survival-at-any-cost bias. Journal of Medical Ethics, 40(4), 246-250. https://doi.org/10.1136/medethics-2012-100700; Rakić, V. (2014). Voluntary moral bioenhancement is a solution to Sparrow's concerns. The American Journal of Bioethics : AJOB, 14(4), 37-38. https://doi.org/10.1080/15265161.2014.88924

${ }^{6}$ Rakić, V. (2017). The Issues of Freedom and Happiness in Moral Bioenhancement: Continuing the Debate With a Reply to Harris Wiseman. Journal of Bioethical Inquiry, 14(4), 469-474. https://doi.org/10.1007/s11673-017-9805-x

${ }^{7}$ Rakic, V. (2015). How Moral Is (Moral) Enhancement? We Must Create Beings with Moral Standing Superior to Our Own. Cambridge Quarterly of Healthcare Ethics, 24, 58-65. https://doi.org/10.1017/S0963180114000309

${ }^{8}$ Wiseman, H. (2014). SSRIs as Moral Enhancement Interventions: A Practical Dead End. AJOB Neuroscience, 5(3), 21-30. https://doi.org/10.1080/21507740.2014.911214; Crockett, M. J. (2014). Moral bioenhancement: a neuroscientific perspective. Journal of Medical Ethics, 40(6), 370-371. https://doi.org/10.1136/medethics-2012-101096; Wiseman, H. (2016). The Myth of the Moral Brain: The Limits of Moral Enhancement. MIT Press; 
harm is a matter of public health. Zambrano argues that public health interventions aimed at preventing or reducing harm (such as covert MBE) can permissibly restrict liberties if, and only if, three conditions obtain. These conditions are (a) that the harm is specific and identifiable; (b) that the mechanism by which the harm will occur is identifiable; and (c) that there is direct empirical evidence that the threat of harm is immediate or imminent or that it would be an immediate threat if there were no intervention. Zambrano offers examples of liberty-restricting public health interventions that meet these conditions. Quarantine meets all conditions: the spread of harmful disease is a specific and identifiable threat; we generally know how this spread occurs; and we have lots of evidence that these diseases can spread without proper isolation procedures. Similarly, pertussis vaccines meet the conditions. The harms associated with pertussis are specific and identifiable (whoop!); the mechanism by which it spreads is identifiable (whoop!); and we have direct empirical evidence that this threat was immediate or imminent when "many children failed to become vaccinated."

The problem, according to Zambrano, is that the interventions aimed at preventing ultimate harm don't satisfy these conditions. First, the harms that constitute ultimate harm are not specific or identifiable. Second, whatever these harms end up being, we have no idea how they are going to occur. Third, we have no direct empirical evidence that they are immediate or imminent, even in the absence of the liberty-restricting intervention. Since conditions (a)-(c) are necessary and sufficient for the permissibility of liberty-restricting public health interventions aimed at preventing or reducing harm, and the prevention of ultimate harm using MBE fails to meet these conditions, liberty-restricting public health interventions such as covert MBE are not permissible. Thus, the truth of the conditions (a)-(c) undermines my argument that considering

${ }^{9}$ Op. cit. note 1, p. 2 
compulsory MBE through the lens of public health ethics warrants a covert administration of MBE.

For the sake of expediency, I grant that the prevention of ultimate harm using covert MBE fails to meet the conditions. That leaves the conditions themselves. They are far too strong, setting the bar for permissible liberty restrictions in the name of public health much too high. Here are some of the important liberty-restricting public health interventions that are impermissible, if conditions (a)-(c) are true: taxes on tobacco, fluoridated water, isolation of people who have newly discovered infectious disease, or compulsory MMR vaccines.

Taxes by their nature restrict liberty. When they are levied on the purchase of tobacco products, a person's liberty to use tobacco products is restricted. Taxes levied on tobacco products are public health interventions. ${ }^{10}$ However, for the person whose liberty is restricted (i.e., the person buying the product), the harm to them is not specific or identifiable. True, there is a wide variety of harms that the person might experience, or they might not experience any harm at all. Thus, taxes on tobacco products fail to meet condition (a). Furthermore, of the merely potential harms of using tobacco, they are neither immediate nor imminent — often they occur many years later, if at all, which suggests taxes on tobacco products also fail to meet condition (c). Even if we consider, for example, the threat of cancer that is distal to the actual liberty-restricting intervention and mediated by many other factors, we don't know the mechanism by which the harm occurs. At some fine-grained level of specificity, we don't know how inhaling cigarette smoke results in the harms associated with lung cancer. And even if we

10 The Centers for Disease Control and Prevention notes that tobacco control is one of the top ten public health achievements of 2001-2010. Ten Great Public Health Achievements-United State 2001-2010, https://www.cdc.gov/mmwr/preview/mmwrhtml/mm6019a5.htm, accessed July 3, 2019. 
do know now, there was a time when we didn't, a time when all we had were strong associations. But even then taxes on tobacco products were permissible.

Relatedly, Zambrano's conditions imply that liberty-restricting public health interventions based on mere associations are impermissible, as they would fail to satisfy condition (b). Suppose a public health organization discovers a strong association between spinach from a particular geographic region and a high prevalence of a food-borne illness. According to Zambrano's conditions, it would be impermissible for that organization to intervene, for example by orchestrating a recall of spinach from that region, because the mechanism is not identifiable (i.e., which farm is making people sick). Or consider a less mundane example of an outbreak of a newly discovered disease. According to condition (b) it is impermissible to restrict liberties, such as the liberty to travel, until we know the mechanism by which the harm occurs. But with newly discovered diseases that discovery can take a long time, a time during which many more people may acquire the disease in the absence of the libertyrestricting intervention. We might say the same thing about quarantine of a person who appears to have a previously unobserved infectious disease. Absent knowledge of the mechanism by which harm occurs (e.g., how it infects others), Zambrano's conditions imply that quarantine of such an individual would be morally impermissible, even if there is strong evidence that the new disease is highly infectious and likely to harm others (both of which are a matter of associated, not necessarily causal, factors). Such a person couldn't be permissibly quarantined until we knew the mechanism of infection, not even while researchers investigate that mechanism.

Other common and important liberty-restricting public health interventions aimed at preventing harm would also be impermissible, by Zambrano's conditions. Flouridated water aims to prevent the harm that results from dental caries and imposes liberty restrictions on the consumption of public water. The harm from dental caries is neither immediate nor imminent, 
nor would it be without the intervention. Rather, it is distant and easily prevented by other means. Its permissibility is justified by the fact that it is the most efficient way to prevent dental caries in some segments of society for whom accessing those other means is difficult. The MMR vaccine wouldn't be permissibly compulsory, for the threat of harm from not getting the vaccine is neither immediate nor imminent (the absolute risk of contracting measles is very low, even for those unvaccinated), ${ }^{11}$ and can be prevented by other interventions.

In short, none of Zambrano's conditions for permissible liberty-restricting public health interventions aimed at preventing or reducing harm are necessary. Such interventions may be permissible even if the harm is not specific or identifiable (e.g., tobacco use), the mechanism of harm is unknown (e.g., newly discovered diseases), or the threat is distant and mediated by other factors (e.g., fluoridated water). Zambrano's conditions are too strong and should be rejected. They are therefore no threat to my claim that public health ethics warrants compulsory covert MBE.

Zambrano might say that lung cancer or dental caries are immediate, or that even when we don't know the specific mechanism of the spread of disease we know that it can be spread by human contact. But such replies would invite a greater problem for Zambrano's conditions: all three of the conditions are so vague that they appear to not be very useful. What level of specificity is necessary or sufficient? Must we specify the harm at the genetic level? What degree of ignorance of the mechanism is allowable? Certainly too strict is a requirement that for a liberty-restricting public health intervention to be permissible we must have complete knowledge of the mechanism by which the harm occurs, because at every point at which we might ask, "Do

${ }^{11}$ Diekema, D. S. (2015). Physician Dismissal of Families Who Refuse Vaccination: An Ethical Assessment. Journal of Law, Medicine and Ethics, 43(3), 654-660. https://doi.org/10.1111/jlme.12307 
we know everything?" the right answer will always be, "No." What is immediate or imminent? If lung cancer is immediate, then why not the next generation's displacement due to global warming?

\section{Autonomy and covert MBE}

Zambrano's second point of contention is that covert MBE undermines a person's autonomy to a greater degree than does overt $\mathrm{MBE}$, contrary to my claim that an overt $\mathrm{MBE}$ is more undermining. For a thought or behavior to be autonomous, it plausibly must meet two conditions. First, autonomy requires independence from external influence. Second, autonomy requires that the thought or behavior be authentic to the person. I argue that when it comes to the independence condition, a covert MBE and overt MBE are on the same footing. If it's external influence that undermines independence, and the intervention is the same whether it is administered covertly or overtly, it makes no difference to the independence of the thought or behavior whether one knows about it.

Zambrano disagrees. He claims that "under an overt program in which people are aware that they are being morally enhanced, people will be put in an epistemic position to combat the effects of the manipulation, and then either embrace or reject their newfound desires, values, and beliefs." ${ }^{12}$ But under an effective covert MBE program the enhanced would not be in such an epistemic position. This difference in epistemic position implies that the independence of those being covertly enhanced is compromised in a way that those being overtly enhanced are not.

${ }^{12}$ Op. cit. note 1, p. 4. 
In a 2016 article in this journal I argue that there is no such thing as an effective compulsory overt MBE. ${ }^{13}$ The reasons for this claim are all centered by the idea that knowing one's moral capacities are being manipulated undermines the achievement of the intended effect. The only way to make compulsory MBE effective, because of our epistemic positions and dispositions, is for it to be administered covertly. Zambrano says this is beside the point, but it isn't if we are to compare side by side covert and overt programs.

If I am right in the 2016 article, then the epistemic position that Zambrano highlights undermines the effectiveness of MBE. If it is ineffective, then the program is not ethically justified. Effectiveness goes hand in hand with the population's epistemic position: the stronger the population's epistemic position, the less effective an overt program will be and vice versa. If the overt $\mathrm{MBE}$ is presumed to be effective, as it must be if we are to compare side by side covert and overt MBE programs, then the population's epistemic position must be much weaker than Zambrano imagines. In particular, the degree to which people could access and control their own mental states for an overt MBE program to be effective would have to be very limited, certainly more limited than what Zambrano needs to support his claim that people could embrace or reject their newfound beliefs. In short, I deny that the enhanced population's epistemic position in an effective overt program can be what Zambrano says it would be.

Even so, the route of enhancement, whatever it ends up being, need not be any more invasive to one's moral capacities than is the frame of a belief to a person's mental state. Framing effects are those effects upon the content of a mental state that result from the immediate context of the thought, such as the words used to express a proposition or, literally, the color of the frame surrounding an image. They happen all the time. Though it is not a safe

\footnotetext{
${ }^{13}$ Crutchfield, P. (2016). The Epistemology of Moral Bioenhancement. Bioethics, 30(6). https://doi.org/10.1111/bioe.12239
} 
and effective MBE for widespread use, oxytocin may enhance some people's moral capacities in some conditions. Indeed, researchers believe oxytocin works by making social cues more salient. ${ }^{14}$ That is, oxytocin, and so MBE, may work by exploiting framing effects.

However, we are typically not in a position to "combat" framing effects, even when we are made aware of the effect. Relative to framing effects, our epistemic position is weak. A person looking at two squares of equal shade of gray, one framed by a darker gray and one framed by a lighter gray, is going to see the squares as different shades of gray even after being told that their apparent difference is due entirely to the difference in frames. Similar effects are frequent in our daily lives, such as when we get on the bus, buy groceries, or open our web browsers or social media. Even when we know about the effects, the second-order process of evaluating our own mental states is itself biased and framed by external factors.

If framing effects undermine autonomy by compromising the independence of mental states, then we are rather less autonomous than we think, in which case there is nothing unique about MBE. But if framing effects don't undermine the independence condition, then there is no reason to think that $\mathrm{MBE}$ would undermine the independence condition, regardless of whether the MBE is covert or overt.

Zambrano also challenges my claim that an overt MBE program compromises the authenticity condition on autonomy to a greater degree than a covert MBE program. My claim is that in a covert MBE program the enhanced are more likely to accept the new moral capacities as their own. Since a covert and overt MBE program compromise the independence condition to the same degree, given that an overt MBE program compromises the authenticity condition more so

\footnotetext{
${ }^{14}$ Shamay-Tsoory, S. G., \& Abu-Akel, A. (2016). The Social Salience Hypothesis of Oxytocin. Biological Psychiatry, 79(3), 194-202. https://doi.org/10.1016/j.biopsych.2015.07.02
} 
than a covert program, an overt program undermines autonomy to a greater degree than a covert program.

Zambrano appeals to the idea of an evil genius who directly and covertly manipulates the mental states of people such that their moral capacities are downgraded rather than enhanced. He claims that if I am right about covert MBE not compromising authenticity, then the authenticity of the evil genius's victims' newfound desires and beliefs is also not compromised - their downgraded moral capacities are similarly authentic. His response is that this is "surely implausible, for the people's newfound desires are the product of the intentional manipulation of another agent, which means that the desires are not their own."15

Zambrano is right that I must say the same thing about the covert evil genius that I say about covert MBE. However, in neither case is authenticity compromised. Zambrano is thinking of the authenticity condition as being satisfied only if the new capacities are in fact one's ownthat they merely appear to be one's own is insufficient. But this conception of authenticity must be incorrect, if any of our mental states are authentic. It can't be that for a state to be authentic it must in fact be one's own, because if it is necessary, then none of our states are authentic. All of a person's mental states are caused by something external to them. In the parlance of contemporary Bayesian accounts of belief formation, they are either caused by the "priors" that are the product of evolution and so external to our person, the "posteriors" in the form of information we gather from the world external to our person, or an interaction between the two. None of our mental states are in fact our own. Covert MBE or a covert evil genius compromises authenticity no more so than the display of watermelons at the front of the grocery store which induces the thought, "I'd really like some watermelon." Are we to say that when one reaches down and grabs a watermelon the thought and subsequent behavior are not autonomous? I'm

${ }^{15}$ Op. cit. note 1, p. 4. 
indifferent to the answer. But if the answer is "Yes," then we have rather less autonomy than we think, and covert MBE is not uniquely problematic. If the answer is "No," then covert MBE doesn't undermine authenticity. In either case covert MBE is no special threat to our autonomy.

\section{Conclusion}

The relations between the epistemology of MBE, its effectiveness, and potential restrictions on a person's liberty or autonomy are interesting and understanding them critical to the realization of administering MBE, presuming in the first place that it's possible to do so. Zambrano is right to highlight these relations. Further, how epistemology, effectiveness, liberty and autonomy all relate hinges in part on how strong the targeted population's epistemic position is relative to the targeted effects. The stronger a population's epistemic position relative to the targeted effects - the greater their ability to access and control their new moral beliefs and the reasons for those beliefs - the greater requirement that the enhancement be administered covertly for it to be effective, which has controversial ethical implications. Although covert administration doesn't threaten liberty or autonomy in any impermissible way, to understand whether covert or overt MBE is better, we need to know how strong the population's epistemic position is likely to be. This is partly an empirical matter. If it's a weak position, and members of the population are helpless to "combat" the enhancement, then an overt MBE may be preferable; or the belief that one is being manipulated might be too great a burden, justifying instead a covert MBE. Either way, we need to better understand the epistemic positions of those who receive moral enhancements, because it matters to the method of administering MBE. 